\title{
Impact of Personal Resource Inventory on Psychological Well-Being and Depression in Pakistani Sample
}

\author{
Aisha Bano*, Alay Ahmad \\ Department of Psychology, Preston University, Islamabad, Pakistan \\ Email address: \\ ms_fairytale@outlook.com (A. Bano) \\ ${ }^{*}$ Corresponding author \\ To cite this article: \\ Aisha Bano, Alay Ahmad. Impact of Personal Resource Inventory on Psychological Well-Being and Depression in Pakistani Sample. \\ International Journal of Psychological and Brain Sciences. Vol. 6, No. 5, 2021, pp. 66-70. doi: 10.11648/j.ijpbs.20210605.11
}

Received: May 21, 2021; Accepted: July 19, 2021; Published: September 27, 2021

\begin{abstract}
The objective of the study was to find out the impact of Personal Resource variable on psychological well-being and depression in Pakistani population. Study design was cross-sectional research design, survey method. The study was conducted in privately registered, semi-government and government institutions of Rawalpindi and Federal Capital Territory during the year 2016-2018. Data was collected using purposive random sampling from 200 employees working in private, semi-government and government organizations. 55.5\% were males and 44.5\% were females; Mean age = 26.81 (SD = 5.7); Mean job experience was $\mathrm{M}=4.5$; $\mathrm{SD}=5.49$; highest qualification was $35 \%$ Masters among Matric, Inter, Graduation, M.Phil and $\mathrm{PhD}$. Results of the study showed that regression analysis showed that Personal Resource variable accounts for $21 \%$ of variance in psychological wellbeing and $27 \%$ of variance in depression. The alpha coefficient reliability for the newly constructed four factors of self-efficacy, resilience, hope and optimism based questionnaire, was found to be $\alpha=0.86$ and split half reliability coefficient was .74 and .79 on Pakistani sample which was sufficiently adequate. Hence our objective of the study which was to find out the impact of Personal Resource variable on mental health and depression within Pakistani culture was thus established.
\end{abstract}

Keywords: Personal Resource, Psychological Well-being, Depression, Resilience, Confidence, Determination, Self-regulation, Self-control, Persistence

\section{Introduction}

World Health Organization (WHO) defines health as, "A state of complete physical, mental and social well-being, and not merely the absence of disease" [16]. The term "personal resources" is used for those personality strengths [8]. which have positive dimensionality as their unique feature. Many researches have been conducted in the west to describe the positive features of such personal resource model. Luthans, Youssef, and Avolio operationally defined personal resource through virtues (individual strengths) of hope, resilience, optimism and self-efficacy $[5,6]$. Study results of Fredrickson, Cohn, Coffey, Pek, and Finkel that positive emotions over a period of time increases personal resources of increased mindfulness, purpose in life, social support, life satisfaction and decreases depressive symptoms [4]. The study results state that positive emotions build personal resource repertoire over a period of time and thus increases individual adaptiveness to adversities whereas contrary to this negative affect i.e neuroticism leads to harmful [13] Various researches qualify the four psychological constructs namely hope, self-efficacy, optimism and resilience as personal resource [7] by demonstrating positive correlation with capability for success $[3,10]$; enhanced positive mental health $[5,9,12]$ good organizational fit [14] and negative correlation with depression $[9,11,13]$.

This study conducted in Pakistan will extend the mental health theory under the domain of positive psychology as positive psychological traits are still to be looked for in Pakistani context. Moreover, Pakistan has also been in fight against terrorism with the advent of $21^{\text {st }}$ century and the coming generation has seen an edgy time with respect to healthy psychological maneuvers of joy and happiness. It is here where the interplay of positive and negative dispositional character traits creates difference between fully functioning and non-fully functioning individuals of the 
society. A sound indigenous measure for gauging positive individual traits is therefore needed in order to focus on something more positive rather than negative. Hence the main objective is to overcome the limitation of the manual of psychologist i.e. Diagnostic and Statistical Manual which states only the disorders of psychological nature but seems lacking in its prospect of those positive individual traits that must be buffering against these disorders among robust people?

\section{Subjects and Method}

\subsection{Participants}

Sample of $N=200$ employees from private, government and semi-government organizations. $55.5 \%$ were males and $44.5 \%$ were females; Mean age $=26.81(\mathrm{SD}=5.7)$; Mean job experience was $M=4.5 ; S D=5.49$; highest qualification was $35 \%$ Masters among Matric, Inter, Graduation, M.Phil and $\mathrm{PhD}$ was gathered using simple random sampling.

\subsection{Instruments}

Personal Resource Inventory Urdu (PRI). It is a 24 item scale measuring resilience, confidence, determination, selfregulation, self-control and persistence, with Alpha reliability coefficient of .85 in Urdu Language for the Pakistani population. Responses are scored on six point Likert scale. The mean score on the total scale of PRI is $\mathrm{M}=71.98$ with $\mathrm{SD}=15.56$.

Warwick Edinburg Mental Wellbeing Scale (WEMWBS). The Warwick Edinburg Mental Wellbeing Scale (WEMWBS) is a 14 item scale developed by Waqas Ahmad, Haddad, Taggart, Muhammad., Bukhari, Sami, Batool, Najeeb, Hanif, Rizvi, and Ejaz [15]. The responses are scored on five categories from 'none of the time' to 'all of the time'. It assess previous two weeks period. Total score is an index of magnitude of one's positive psychological functioning. The Cronbach's alpha of WEMWBS is .89 indicating good internal consistency.

Depression Sub-scale of Depression, Anxiety and Stress Scale (DASS). The depression sub-scale of Urdu translated version of Depression, Anxiety and Stress Scale (DASS) (Aslam \& Kamal, 2017) consists of 14 items. The responses are scored on four categories from "did not apply to me at all" to "apply to me very much or most of the time". The total score is an index of magnitude of one's depression. The
Cronbach's alpha $(\alpha=.84)$ indicates satisfactory internal consistency [2].

Ethical Considerations. Ethical issues were besides taken into attention, by abiding by to the ethical principles specified by the Ethical Principles of Psychologists and Code of Conduct (2002) [20]. It includes guaranteeing that participation was voluntary and that privacy was retained.

\subsection{Hypotheses}

Following were the hypotheses:

1) There will be a positive correlation between Personal Resource Inventory (PRI) and Warwick Edinburg Mental Well-Being Scale (WEMWBS) in the given sample.

2) There will be a negative correlation between Personal Resource Inventory (PRI) and Depression Subscale of DASS in the given sample.

3) Personal Resource Inventory will impact the relationship of psychological wellbeing as measured by Warwick Edinburg Mental Well-Being Scale (WEMWBS) and psychological distress as measured by the Depression subscale of Depression, Anxiety and Stress Scale (DASS) in Pakistani sample.

\section{Results}

Table 1 shows the results for convergent validity yielding significant positive correlation of $\left(\mathrm{r}(200)=.46^{* *}\right.$, $\mathrm{p}<.01)$ between Warwick Edinburg Mental Wellbeing Scale measuring positive psychological wellbeing and Personal Resource comprising of resilience, confidence, determination, self-regulation, self-control and persistence. Results for divergent validity yielded significant negative correlation $(\mathrm{r}(200)=-.52 * *, \mathrm{p}<.01)$ between Depression subscale of DASS measuring depression symptoms and Personal Resource. Tables 2 and 3 shows Linear Regression analysis using PRI as predictor variable for Warwick Edinburgh Mental Well Being Scale and Depression scale showed that Personal Resource Inventory (PRI) was a highly significant predictor of the relationship between the variables, accounting for $21 \%$ of the variance in Positive Psychological Well-Being $(\beta=$ $52.64, \mathrm{p}<.001)$ and $27 \%$ of the variance in Depression $(\beta$ $=.74 .27, \mathrm{p}<.000)$.

Table 1. Pearson Correlation between PRI and Warwick-Edinburgh Mental Well-Being Scale (WEMWBS) and Depression Subscale (DASS).

\begin{tabular}{lll}
\hline & Warwick-Edinburgh Mental Well-Being Scale (WEMWBS) $(\boldsymbol{N}=\mathbf{2 0 0})$ & Depression Subscale (DASS) (N=200) \\
\hline Personal Resource Inventory (PRI) & $.46^{* *}$ & $-.52^{* *}$ \\
Sub-scales & & \\
resilience & $r=.37^{* *}, p<.01$ & $r=-.42^{* *}, p<.01$ \\
confidence & $r=.34^{* *}, p<.01$ & $r=-.42^{* *}, p<.01$ \\
determination & $r=.39^{* *}, p<.01$ & $r=-.40^{* *}, p<.01$ \\
self-regulation & $r=.26^{* *}, p<.01$ & $r=. .34^{* *}, p<.01$ \\
self-control & $r=.22^{* *}, p<.01$ & $r=.-28^{* *}, p<.01$ \\
persistence & $r=.26^{* *}, p<.01$ & $r=-.24^{* *}, p<.01$ \\
\hline
\end{tabular}

$* * \mathrm{p}<.01$ 
Table 2. Linear Regression analysis using Personal Resource as predictor variable for Warwick Edinburgh Mental Well Being Scale (N = 200).

\begin{tabular}{lllll}
\hline Variables & B & $\boldsymbol{S E} \boldsymbol{\beta}$ & $\boldsymbol{\beta}$ & \\
\hline Constant & 27.28 & 3.0 & & \\
PRI & .24 & .03 & .46 & $9.07 * *$ \\
\hline
\end{tabular}

$\mathrm{R}^{2}=.21$, Adjusted $\mathrm{R}^{2}=.21, * * p<.001 ; * * * \mathrm{p}<.0001$

Note. Please read b as Unstandardized Coefficients; SE as Standard Error; and $\beta$ as Standardized Coefficients.

Table 3. Linear Regression analysis using Personal Resource as predictor variable for Depression Scale $(N=200)$.

\begin{tabular}{lllll}
\hline Variables & B & $\boldsymbol{S E} \boldsymbol{\beta}$ & $\boldsymbol{\beta}$ & \multicolumn{1}{c}{} \\
\hline Constant & 40.40 & 2.4 & $16.70^{* * *}$ \\
PRI & -.22 & .026 & -.52 & $-8.6^{* * *}$ \\
\hline
\end{tabular}

$\mathrm{R}^{2}=.30$, Adjusted $\mathrm{R}^{2}=.30, * * * p<.000$

Note. Please read b as Unstandardized Coefficients; SE as Standard Error; and $\beta$ as Standardized Coefficients.

\section{Regression plot for PRI \& WEMWBS}

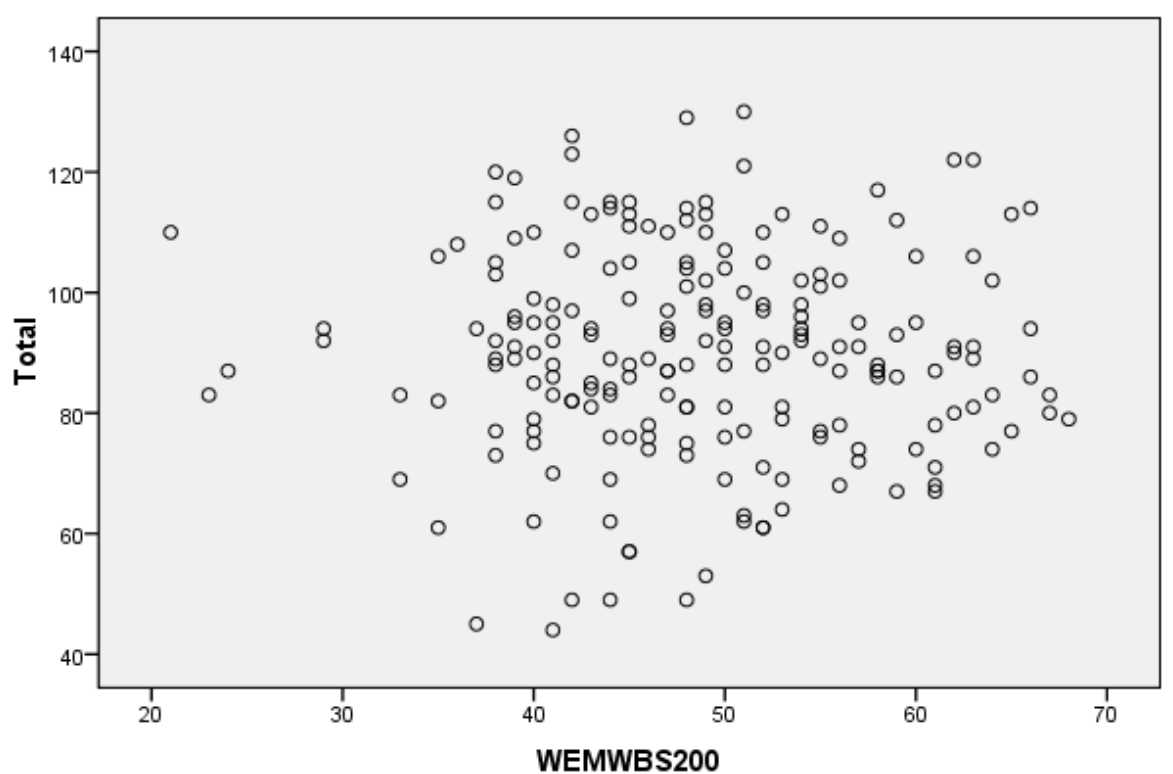

Figure 1. Regression plot showing the relationship between Personal Resource Inventory and Warwick Edinburg Mental Well-being scale.

\section{Regression plot for PRI \& DASS}

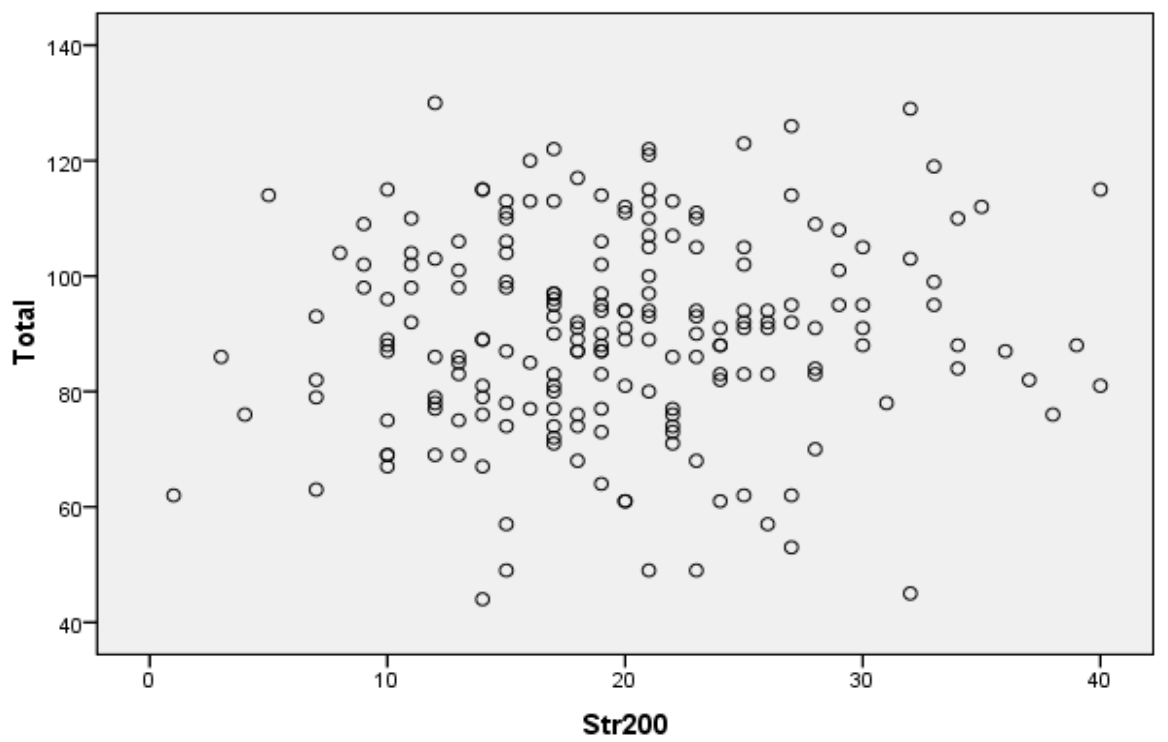

Figure 2. Regression plot showing the relationship between Personal Resource Inventory and Depression Scale. 


\section{Discussion}

A correlational analysis of indigenized Personal Resource Inventory with Warwick Edinburgh Mental Wellbeing Scale shows a significant Positive and with Depression Scale a significant negative correlation coefficient. Warwick Edinburgh Mental Wellbeing Scale is a reliable and valid measure of mental wellbeing whereas, Depression subscale of Depression Anxiety and Stress Scale (DASS) is a reliable and valid measure of Depression in Pakistani population [1]. Hence, from the study results it can be concluded that Personal Resource which is entirely based on state like personality dimensions of resilience, confidence, determination, self-regulation, self-control and persistence significantly relates to mental well-being and depression. Similar results affirm that the self-efficacy variable components of Personal Resource may serve as a protective factor against depression as shown in a study by Rehman and Tabassum which reports inverse correlation of -.35 between self-efficacy and emotional, cognitive and somatic symptoms of depression [17].. There is substantial need for determining the proactive protective natured factor pertaining to human personality which could demonstrate the potential to improve mental health condition in Pakistani population. As the study results by Haq, Riaz, Naseem, Tahir and Ahmed for determining the mental health profile of students related to the field of medical Quetta, Pakistan showed that $58.3 \%$ had poor mental health [18]. The researchers prompted the need to identify the factors which have the potential to improve mental health of the medical students and organize programs based on those factors of personality strengths. Furthermore, the importance is also evident from the study results of Sarwat Jahan Khanam and Syeda Razia Bukhari such that depression negatively relates to academic performance [19].

\section{Limitations of the Study}

Large sample size may be used to compute further analysis in order to establish norms, concurrent validity and reliability of the scale. Data is collected with the help of self-rated scales however, these ratings may be cross validated with the ratings of workplace performance criteria.

\section{Recommendations}

Hence it was concluded that Personal Resource Inventory is a valid and reliable research questionnaire in Pakistani culture. Its' usefulness in determined for intervention programs especially designed to enhance mental health and reduce depression / stress for the sake of healthy personality.

\section{Conclusion}

Personal Resource Inventory usefulness in determined for intervention programs especially designed to enhance mental health and reduce depression / stress. Future researches need to provide evidence that support the results suggesting that by strengthening the positive personality traits a proactive, preemptive and curative support to individuals is provided. By employing intervention programs the researcher could drive the factor into action and make use of the variable for individual at structural level.

\section{References}

[1] Asghar N., \& Riaz, N. (2017). State-Trait Resilience and Mental Health Outcomes among Adults: Comparative Study of Pakistan and Kingdom of Saudi Arabia. Pakistan Journal of Medical Research, 56 (2), p. 58-62. Retrieved from http://pjmr.org.pk/assets/17-2015-mental-healthoutcomes\%2Cpjmr-2017-(2)\%2Cp.pdf

[2] Aslam, N. \& Kamal, A (2017). Translation, Validation and Effectiveness of Depression, Anxiety and Stress Scale (DASS-21) in assessing the psychological Distress among flood affected individuals. Journal of Pakistan Psychiatric Society, 14 (4), p. 16-20. Retrieved from, http://www.jpps.com.pk/article/15198028712310-

Translation $\% 20$ Validation $\% 20$ and $\% 20$ Effectiveness $\% 20$ of $\% 2$ 0Depression, $\% 20$ Anxiety $\% 20$ and $\% 20$ stress $\% 20$ scale $\% 20$ (DA SS-

21)\%20in\%20Assessing\%20the\%20psychological\%20Distres s\%20Among\%20Flood\%20Affected\%20Individuals.pdf

[3] Aybas, M. \& Acar, A. C. (2017). The Effect of Human Resource Management Practices on Employees' Work Engagement and the Mediating and Moderating Role of Positive Psychological Capital. International review of management and marketing, 7 (1), 363-372. Retrieved from file://C:/Users/user/Downloads/3534-10541-1-PB\%20(1).pdf

[4] Fredrickson, B. L, Cohn, M. A, Coffey, K. A, Pek, J, \& Finkel, S, M. (2011). Open Hearts Build Lives: Positive Emotions, Induced Through Loving-Kindness Meditation, Build Consequential Personal Resources. J Pers Soc Psychol, J Pers Soc Psychol. 2008 Nov; 95 (5): 1045-1062, doi: 10.1037/a0013262.

[5] Luthans, F., Youssef, C. M., \& Avolio, B. J. (2007). Psychological Capital: Developing the human competitive edge. New York, NY US: Oxford University Press.

[6] Luthans, F. \& Youssef, C. M. (2017). Psychological Capital: An Evidence based positive approach. Annual Reviews of Organizational Psychology and Organizational Behavior, 4, pp. 339-336. doi: 10.1146/annurev-orgpsych-032516-113324.

[7] Manzoor, S., R., Khattak I., A., \& Hassan, S. (2015). Psychological Capital and counterproductive work behavior with intrusion of employee performance: Study from KP Pakistan Universities. City University Research Journal, 5 (2), 372-383.

[8] Park, N., Peterson, C., \& Seligman, M. E. P. (2004). Strengths of character and well-being. Journal of Social and Clinical Psychology, 23 (5), 603-619. doi: 10.1521/jscp.23.5.603.50748.

[9] Qhomashi, S., Ahmadi, M., Abbasi, M., \& Salehi, H. (2016). Study of Adolescents Psychological Capital and its impact on crime trends (Isfahan). Iran J Med Law, 10 (37), p 171-193. 
[10] Rauf, K., \& Farooq, A. (2014). Adaptation and Validation of counterproductive work behavior checklist (45 and 32). International Journal of Novel Research in Humanity and Social Sciences, 1 (1), pp. 39-49. Retrieved from www.noveltyjournals.comPage|39

[11] Riaz, H., Riaz, M., \& Batool, N. (2014). Positive Psychological Capital as predictor of internalizing psychological problems among flood victims. Journal of Indian Academy of Applied Psychology, 40 (1), 102-112.

[12] Selvaraj, P. R. (2015). Using positive psychological capital to predict mental health in college students: Implications for counseling and higher education (Doctoral thesis). Retrieved from

file://D:/Draft\%20synopsis/Helpful\%20articles/Selvaraj,\%20 Priscilla\%20accepted\%20dissertation\%2005-01$15 \% 20 \mathrm{sp} \% 2015 . \mathrm{pdf}$

[13] Soltaninejad, A. Fathi-Astiani, A. Khodabakhsh, A. Mirsharafoddini, H. S. Nikmorad, A., \& Pilevarzadeh, M. (2014). Personality factors underlying suicidal behavior among military youth. Iran Red Cresccent Med J, 6 (4). doi: 10.5812/ircmj. 12686.

[14] Therasa, C. \& Vijayabanu, C. (2016). The impact of big five personality traits and positive psychological strengths towards job satisfaction: a review. Periodica polytechnic Social and Management sciences, 23 (2), 142-150. doi: 10.3311/PPso.7620.

[15] Waqas, A., Ahmad, W., Haddad, M., Taggart, F. M., Muhammad, Z., Bukhari, M. H., Sami, S. A., Batool, S. M., Najeeb, F., Hanif, A., Rizvi, Z. A. \& Ejaz, S. (2015). Measuring the wellbeing of health care professionals in the Punjab: a psychometric evaluation of the Warwick Edinburgh
Mental Wellbeing Scale in a Pakistani population. PeerJ 3: e1264; doi 10.7717/peerj.1264.

[16] World Health Organization. (2010). WHO Healthy workplace. Framework and Model: Background and Supporting Literature and Practices. Healthy workplaces: A Model for Action: For employers, workers, Policymakers and Practitioners. Geneva: WHO. Retrieved 20 April 2017 from http://www.who.int/occupational_health/publications/healthy_ workplaces_background_documentdfinal.pdf

[17] Rehman, G. \& Tabassum, U. (2005). The relationship between self efficacy and depression in physically handicapped children. Journal of Pakistan Psychiatric Society, 2 (1), p. 37. Retrieved from

http://www.jpps.com.pk/article/therelationshipbetweenselfeffica cyanddepressioninphysicallyhandicappedchildren_2239.html

[18] Haq, Riaz, Naseem, Tahir and Ahmed (2017). Evaluation of mental health of students related to medical fields in Quetta, Pakistan: A cross sectional study. Journal of Pakistan Psychiatric Society, 14 (1), p. 28-31. Retrieved from http://www.jpps.com.pk/article/14937977155504o.\%20Evaluation $\% 20 \mathrm{of} \% 20$ Mental $\% 20$ Health $\% 20$ of $\% 20$ Stud ents\%20Related\%20to\%20Medical\%20Field\%20in\%20Quett a,\%20Pakista\%20A\%20Corsssectional\%20Study.pdf

[19] Sarwat Jahan Khanam and Syeda Razia Bukhari (2015). Depression as a predictor of academic performance in male and female university students. Journal of Pakistan Psychiatric Society, 12 (2), p. 15. Retrieved from http://www.jpps.com.pk/article/depressionasapredictorofacadem icperformanceinmaleandfemaleuniversitystudents_2472.html

[20] Anastasi, A., \& Urbina, S. (2003). Psychological Testing. $\left(7^{\text {th }}\right.$ ed.). New Delhi: Prentice Hall, Inc. 